\title{
Subtitled Films and Learning Listening Comprehension: A Study in Bulukumba, Indonesia
}

\author{
Anugerah Febrian Syam \\ Andi Qashas Rahman \\ State University of Makassar, Indonesia
}

\begin{abstract}
This present study is aimed at finding out (1) the possible effect of subtitled and non-subtitled movies on students' listening achievement, and (2) the difference between using subtitled and non-subtitled movies in students' listening comprehension. A Comparative study using two groups with a pre-test and posttest design was undertaken in this research. The data were collected using the IELTS listening test. There were two results in the data analysis of IELTS listening test. The first, a general improvement was noted. It was found that both procedures (presenting the movie with or without subtitles) produced a positive effect. Second, the result of movie task data analysis indicated a positive effect for both groups; both groups significantly improved during six weeks. It was revealed that subtitled group exercised a better performance than non-subtitled group.
\end{abstract}

Keywords: Subtitled movies, Non-subtitled movies, The IELTS Listening Test.

\section{INTRODUCTION}

The teaching of listening has attracted a greater level of interest in recent years, more than it did in the past. University entrance exams, school examinations and other examinations now include a listening component, acknowledging that listening skills are a core component of foreign language proficiency.

As listening is assuming greater importance in foreign language classrooms and in language acquisition (Dunkel, 1991), researchers have conducted detailed studies of this skill. One idea that has been a focus is the role of the 
listener as an active processor of the type of knowledge that he/she brings to the context of listening. In other words, there have been investigations of whether the background of the listener has any effect on the process of listening.

Listening plays a significant role in the lives of people. Of the four major areas of communication skills and language development--listening, speaking, reading, and writing. The one that is the most basic is listening. It is evident that children listen and respond to language before they learn to talk. When it is time for children to learn to read, they still have to listen so that they gain knowledge and information needed to follow directions. In the classroom, students have to listen carefully and attentively to lectures and class discussions in order to understand and to retain the information for later recall. Listening is not only the first of the language arts skills developed, it is also the skill most frequently used in both the classroom and daily life. Rankin (1930) suggested that adults spend more than 40 percent of their communication time listening, in contrast with 31.9 percent speaking, 15 percent reading, and 11 percent writing. Clearly, much of the educational process is based on listening skills. Students have to spend most of the time listening to what the teacher says, for instance, giving lectures, asking questions, or giving directions. According to Coakley\&Wolvin(1997), the amount of time that students are expected to listen in the classroom ranges from 42 to 57.5 percent of their communication time. Taylor (1964), on the other hand, estimates that nearly 90 percent of the class time in high school and university is spent in listening to discussion and lectures. Since listening occupies such a large percentage of the communication time of most people, it is therefore advantageous to possess effective listening skills in order to meet the listening demands that occur daily.

In a language classroom, listening ability plays a significant role in the development of other language skills. When students first learn a language, they generally have to listen to the words several times before they are able to recognize and pronounce those words. Listening can also help students build vocabulary, develop language proficiency, and improve language usage (Barker, 1971). Cayer, Green, \& Baker (1971) found that a student's ability to comprehend written material through reading as well as to express themselves through speaking and written communication is directly related to students' maturity in the listening phase of language development. Dunkel (1986) also asserted that developing proficiency in listening comprehension is the key to achieving proficiency in speaking. Not only are listening skills the basis for the development of all other skills, they are also the main channel through which students make initial contact with the target language and its culture (Curtain \&Pesola, 1988). 
SyamE Rahman, Subtitle Films and Learning Listening Comprehension |61

Despite the importance of the listening component in language instruction, English language classes in many countries still emphasize only the skills of reading and writing. This is especially the case of an English as a foreign language (EFL) situation in which the English language is taught as a subject at school and used only inside, but not outside the classroom. EFL students are studying English in their home countries where English is not the dominant native language. Students who are from environments where English is not the language of the country have very few opportunities to hear the real language. These students therefore are not accustomed to hearing the language as it is produced by native speakers for native speakers. Consequently, students from the countries in which English is taught as a foreign language frequently have great difficulty understanding the English spoken to them when they come into contact with native speakers of the language.

Movies can teach people about history, science, human behavior and other subjects. Movies that combine entertainment with instruction make the learning process more enjoyable. In all its forms, cinema is not only an art but also a business. Those who make motion pictures take great pride in their creation, but those creations also become important materials in teaching and learning process especially in English. Learning with movies plays a significant role in the proficiency of learners.

Most studies have proved that presenting movies when teaching listening can have a positive impact on listening comprehension achievement. But only few studies have examined the impact of using subtitles in movies to improve the listening comprehension skills of English language learners. Those few studies suggested that the use of movie subtitles could decrease the amount of new language acquired by language learning students.

\section{METHOD}

\section{Participants}

This study took place in the second year English class at a teacher's college, SekolahTinggiKeguruandanIlmuPendidikan in Bulukumba, Indonesia. The total number of participants in this study was forty students. In this research, the researcher selected one class from four classes at the same level. This class was selected as a research sample because the researcher had had oneyear of teaching experience. The selected participants were assigned randomly into two groups: the group who watched a film with subtitles (the subtitled group) and the group who watched without subtitles (the nonsubtitled group). Each group consisted of 20 students.

\section{Research Design}




\section{$62 \mid$ ELT Worldwide Vol. 1 No. 1}

The subtitled and non-subtitled groups were given a pre-test and a post-test. The pre-test was administered prior to viewing the film to assess their competence in listening comprehension. The post-test was administered to measure possible changes after viewing the film. The aim of this test was to find out the impact of using movies with and without subtitles on the students' listening comprehension levels. This design can be explained schematically, see below.

\begin{tabular}{lll}
1 & 1 & 2 \\
\hline 1 & 2 & 2
\end{tabular}

Figure 1. Research Design (Gay, et al., 2006)

Symbols:

G1 : Subtitled Group

G2 : Non-subtitled Group

O1 : Pre-test

$\mathrm{O} 2 \quad$ : Post-test

$\mathrm{X} 1 \quad$ : Treatment for subtitle group

X2 : Treatment for non-subtitle group

\section{Research Instrument}

The participants of this study first were testedusing the listening sections of IELTS. This IELTS Listening test was designed to assess a wide range of listening skills, including how well the subject understood main ideas and specific factual information; recognized the opinions, attitudes and purpose of a speaker; and followed the development of an argument.

The test in this research was chosen by considering the students' competencies and the participation of the students who had never taken any kind of IELTS test before. There are four listening sections of IELTS. In section one and three, the students hear conversations, while in sections two and four, the students hear monologues. The test consists of six types of format: multiple choice, labeling (a plan, map or diagram), filling in a form, completing a table, completing a flow chart and giving short answers.

The posttest was also given to both groups. The purpose of the test was to measure the students' progress in their listening achievement, if any.

\section{Procedure of Collecting Data}

Before presenting the film, the researcher gave a pre-test to find out students' competencies in listening comprehension. The pre-test was given to both the subtitled and non-subtitled groups. Both groups took four listening sections of IELTS as pre- and post-tests to measure the effects of movies with and without using subtitles. All the sections consisted of 41 
SyamE Rahman, Subtitle Films and Learning Listening Comprehension $\mid 63$

questions. The students in both groups listened two conversations and orientation talks in the four listening sections of IELTS.

The researcher conducted the same experiment with both groups of students. The first group was taught by presenting movies with subtitles while the second group was taught using the same movies, but without presenting the subtitles. Each group was taught using those movies for six meetings. The researcher began the experiment by introducing the theme of the movies. In every meeting, before presenting the movies, the researcher started with a pre-viewing stage and finished the treatment with a post-viewing stage. Each movie was presented in one meeting, which involved three stages: previewing, viewing, and post-viewing.

Table 1. Stages of Experiment

\begin{tabular}{|c|c|}
\hline Subtitled Group & Non-subtitled Group \\
\hline $\begin{array}{l}\text { Previewing } \\
\text { - Introducing the theme and the } \\
\text { characters of the movie }\end{array}$ & $\begin{array}{l}\text { Previewing } \\
\text { - Introducing the theme and the } \\
\text { characters of the movie } \\
\text { - Familiarizing the students with the } \\
\text { words and phrases used in the movie }\end{array}$ \\
\hline $\begin{array}{l}\text { Viewing } \\
\text { - Identifying the person who says the } \\
\text { quotes in the movie } \\
\text { - Identifying the scene in which each } \\
\text { quote occurs } \\
\text { - Predicting the end of the movie }\end{array}$ & $\begin{array}{l}\text { Viewing } \\
\text { - Identifying the person who says the } \\
\text { quotes in the movie } \\
\text { - Predicting the end of the movie }\end{array}$ \\
\hline $\begin{array}{l}\text { Post viewing } \\
\text { - Verifying written results of students' } \\
\text { - } \text { prediction against the actual ending } \\
\text { Examining students' understanding }\end{array}$ & $\begin{array}{l}\text { Post viewing } \\
\text { - Verifying written results of students' } \\
\text { prediction against the actual ending } \\
\text { - Examining students' understanding }\end{array}$ \\
\hline
\end{tabular}

The post-test was given after the six-week experiment was completely done. This post-test was the same IELTS listening test pre-test. This test was aimed at knowing the progress of the students' competencies in listening comprehension after being taught by presenting movies with and without using subtitles.

\section{RESULTS}

\section{Students' IELTS Test Achievement}

The results of the mean scores and standard deviations of the IELTS test for the two groups during six weeks were calculated and are presented in the tables below. A subject was given one point for each correct answer, with the highest possible score being 41 and lowest possible being zero. 


\section{$64 \mid$ ELT Worldwide Vol. 1 No. 1}

\section{Pre-test}

Table 2. The percentage and frequency of the students' pre-test score in subtitled and non-subtitled groups

\begin{tabular}{|c|c|c|c|c|c|}
\hline \multirow{2}{*}{$\begin{array}{l}\text { Category / } \\
\text { Skill Level }\end{array}$} & \multirow{2}{*}{ Score } & \multicolumn{2}{|c|}{ Subtitled Group } & \multicolumn{2}{|c|}{ Non-Subtitled Group } \\
\hline & & $\mathbf{F}$ & $\%$ & $\mathbf{F}$ & $\%$ \\
\hline Expert & $35-40$ & 0 & 0 & 0 & 0 \\
\hline Very Good & $30-34$ & 0 & 0 & 0 & 0 \\
\hline Good & $23-29$ & 0 & 0 & 0 & 0 \\
\hline Competent & $16-22$ & 0 & 0 & 0 & 0 \\
\hline Modest & $11-15$ & 6 & 30 & 3 & 15 \\
\hline Limited & $7-10$ & 8 & 40 & 14 & 70 \\
\hline Extremely Limited & $4-6$ & 6 & 30 & 3 & 15 \\
\hline Intermittent & $2-3$ & 0 & 0 & 0 & 0 \\
\hline Have no ability & 1 & 0 & 0 & 0 & 0 \\
\hline No score & 0 & 0 & 0 & 0 & 0 \\
\hline Total & & 20 & 100 & 20 & 100 \\
\hline
\end{tabular}

In Table 2, the results of the subtitled group pre-test show three skill levels. There are six students who have 5 to 6 points, which indicate an extremely limited skill level, 8 students who have 7 to 10 points, which indicate limited skill level, and 6 students who have 11 to 14 points, which indicate a modest level.

The results of the non-subtitled group pretest also shows three skill levels. There are three students who have 4 to 6 points, which indicate an extremely limited skill level, 14 students who have 7 to 10 points, which indicate a limited skill level, and three students who have 11 to 13 point which indicate a modest level.

In this pretest calculation, both subtitled and non-subtitled group perform at three skill levels: extremely limited, limited and modest. It proves that in the pre-test both groups performed in the same classification range

Table 3. The mean score and standard deviation of the students' pretest

\begin{tabular}{|c|c|c|c|}
\hline Group & Sample & Mean Score & Standard Deviation \\
\hline Subtitled Group & 20 & 8.4 & 2.78 \\
Non-Subtitled Group & 20 & 8.9 & 2.13 \\
\hline
\end{tabular}

The mean score of pretest for the subtitled group is 8.4 that is the limited skill level based on IELTS marking criteria. The non-subtitled group shows 8.9, also classified as the limited skill level. The mean score of thenonsubtitled group is higher than the subtitled-group. The standard deviation of the non-subtitled group is lower than that of the subtitled group $(2.13<2.78)$. 
SyamE Rahman, Subtitle Films and Learning Listening Comprehension $\mid 65$

In order to see the significant difference between pretest of both groups, a paired-sample t-test was run.

Table 4.Significance test of the subtitled and non-subtitled groups pretests

\begin{tabular}{|l|l|l|}
\hline Variable & t & A \\
\hline Pre-test A - Pre-test B & 0.12 & 0.05 \\
\hline
\end{tabular}

Table 4 shows that there is no significant difference between the pre-test of the subtitled group and the pre-test of non-subtitled group. It shows that level of significance is more than $0.05(0.12>0.05)$. This result indicates that the pre-test of both groups statistically have the same result.

\section{Post-test}

Table 5. The percentage and frequency of the students' post-test score in subtitled and non-subtitled groups

\begin{tabular}{|c|c|c|c|c|c|}
\hline \multirow{2}{*}{$\begin{array}{l}\text { Category / } \\
\text { Skill Level }\end{array}$} & \multirow{2}{*}{ Score } & \multicolumn{2}{|c|}{ Subtitled Group } & \multicolumn{2}{|c|}{ Non-Subtitled Group } \\
\hline & & $\mathbf{F}$ & $\%$ & $\mathbf{F}$ & $\%$ \\
\hline Expert & $35-40$ & 0 & 0 & 0 & 0 \\
\hline Very Good & $30-34$ & 0 & 0 & 0 & 0 \\
\hline Good & $23-29$ & 0 & 0 & 0 & 0 \\
\hline Competent & $16-22$ & 3 & 15 & 1 & 5 \\
\hline Modest & $11-15$ & 6 & 30 & 16 & 80 \\
\hline Limited & $7-10$ & 11 & 55 & 3 & 15 \\
\hline Extremely Limited & $4-6$ & 0 & 0 & 0 & 0 \\
\hline Intermittent & $2-3$ & 0 & 0 & 0 & 0 \\
\hline Have no ability & 1 & 0 & 0 & 0 & 0 \\
\hline No score & 0 & 0 & 0 & 0 & 0 \\
\hline Total & & 20 & 100 & 20 & 100 \\
\hline
\end{tabular}

In Table 5, subtitled group post-test scores show three skill levels. There are 11 students who have 7 to 10 points which indicate a limited skill level, six students who have 11 to 14 points which indicate a modest skill level, and three students who have 17 to 19 points which indicate a competent level.

The results of the non-subtitled group pos-ttest also show three skill levels. There are three students who have 9 to 10 points, which indicate a limited skill level, 16 students who have 11 to 15 points, which indicate a modest skill level, and one student who has 17 points which indicate a competent level.

In this posttest calculation, the skill levels of the subtitled and non-subtitled groups increased one level higher than the pretest calculation. It also revealed that both groups no longer had any member scored at the extremely 
limited skill level. It proves that both groups demonstrated positive improvement from the pre-test to post-test.

Table 6. The mean score and standard deviation of the students' post-tests

\begin{tabular}{|l|c|c|c|}
\hline \multicolumn{1}{|c|}{ Group } & Sample & Mean Score & Standard Deviation \\
\hline Subtitled Group & 20 & 10.9 & 3.55 \\
Non-Subtitled Group & 20 & 12.6 & 2.14 \\
\hline
\end{tabular}

Table 6 shows that the mean score of the subtitled group is 10.9 , that is the limited skill level. This indicates that the mean score of the subtitled group rose from 8.4 to 10.9. It shows an improvement of the mean score but that the group remains in the same category or skill level.

The mean score of the non-subtitled group post-test is 12.6 , which is the modest skill level. In the non-subtitled group result, it can be seen that the mean score rose from 8.9 to 12.6. It indicates an improvement of the mean score from the limited to the modest skill level. This result actually did not indicate a positive effect because modest skill level is less than the standard of the good level in the IELTS marking criteria.

In order to see the statistically significant difference between post-test results of both groups, a paired-sample t-test was run.

Table 7. Test of significance of students' posttest

\begin{tabular}{|c|c|c|}
\hline Variable & $\mathbf{t}$ & $\boldsymbol{\alpha}$ \\
\hline Posttest A - Posttest B & 0.00 & 0.05 \\
\hline
\end{tabular}

Table 7 shows that level of significance is less than $0.05(0.00<0.05)$. It indicates that there is a statistically significant difference between the posttest of the subtitled group and the non-subtitled group.

From the total average scores obtained by the groups, it can be seen that the mean score of the non-subtitled group (NSG) was substantially higher than subtitled group (SG). These results verified that students viewing movies without subtitles outperformed the students viewing movies with subtitles.

\section{Test of Significance}

In order to determine the differences between pre-test and post-test between two groups, a paired-samples t-test was run. The results of this test revealed that differences between the groups were significant.

Table 8. Paired-samples T-Test

\begin{tabular}{|l|c|c|}
\hline \multicolumn{1}{|c|}{ Variable } & t & $(\boldsymbol{\alpha})$ \\
\hline Subtitled Group & 0.00 & 0.05 \\
Non-Subtitled Group & 0.00 & 0.05 \\
\hline
\end{tabular}


SyamE Rahman, Subtitle Films and Learning Listening Comprehension $\mid 67$

Table 8 illustrates the results of the comparison for the IELTS tests during the six weeks. It shows that the difference between the two levels of significance is less than $0.05(0.00 \& 0.00<0.05)$. As can be observed, there is a significant difference between the results of pre-test and post-test between the two groups.

\section{Students’ Movie Task Achievement}

Table 9. The difference of mean score and standard deviation between subtitled and non-subtitled groups in movie tasks

\begin{tabular}{|c|c|c|c|c|}
\hline \multirow{2}{*}{ Movie Task } & \multicolumn{2}{|c|}{ Subtitled Group } & \multicolumn{2}{c|}{ Non-Subtitled Group } \\
\cline { 2 - 5 } & Mean Score & $\begin{array}{c}\text { Standard } \\
\text { Deviation }\end{array}$ & Mean Score & $\begin{array}{c}\text { Standard } \\
\text { Deviation }\end{array}$ \\
\hline Movie 1 & 8.65 & 2.96 & 5.9 & 2.77 \\
Movie 2 & 11.3 & 1.78 & 8.3 & 2.27 \\
Movie 3 & 16.3 & 2.47 & 11.7 & 1.69 \\
Movie 4 & 17.5 & 2.33 & 12.25 & 1.62 \\
Movie 5 & 17.45 & 1.5 & 12.8 & 3.05 \\
Movie 6 & 10.95 & 1.15 & 10.05 & 1.23 \\
\hline
\end{tabular}

\section{Movie 1: We Bought A Zoo}

The task consisted of 19 items with the lowest possible score being 0 and the highest possible score 19. The mean score of the subtitled group is 8.65 , while the non-subtitled group shows 5.9. This indicates that the mean score of the subtitled group is better than that of the Non-Subtitled group. The highest score shows 13 for Subtitled group and 11 for Non-Subtitled group. These calculations indicate that the subtitled group hadbetter results than the non-subtitled group.

\section{Movie 2: The Odd Life of Timothy Green}

The task consisted of 20 items with the lowest possible score being 0 and the highest possible being 20. The mean score of the subtitled group is 11.3, while the non-subtitled group shows 8.3. It indicates that the mean score of the subtitled group is better than that of the non-subtitled group. The highest score shows 14 for the subtitled group and 11 for the non-subtitled group. In this task, the calculations indicate that the subtitled group had better results than the non-subtitled group.

\section{Movie 3: National Treasure 2 (Book of Secrets)}

The task consisted of 21 items with the lowest possible score being 0 and the highest possible being 21. The mean score of the subtitled group is 16.3, while the non-subtitled group shows 11.7. It indicates that the mean score of subtitled group is better than that of the non-subtitled group. The highest score shows 19 for subtitled group and 16 for the non-subtitled group. 
Again, thecalculations indicate that the subtitled group had better results than the non-subtitled group.

\section{Movie 4: The Day Earth Stood Still}

The task consisted of 21 items with the lowest possible score being 0 and the highest possible being 21. In this task, the mean score of the subtitled group is 17.5 , while the non-subtitled group shows 12.25 . It indicates that the mean score of the subtitled group is better than that of the non-subtitled group. The highest score shows 21 for the subtitled group and 15 for the non-subtitled group. These calculations indicate that the subtitled group had better results than the non-subtitled group.

\section{Movie 5: Flight Plan}

In this movie, the task consisted of 19 items with the lowest possible score being 0 and the highest possible being 19. The mean score of the subtitled group is 17.45 , while the non-subtitled group shows 12.8. It indicates that the mean score of the subtitled group is better than that of the non-subtitled group. The highest score shows 19 for the subtitled group and 18 for the non-subtitled group. These calculations also indicate that the subtitled group had better results than the non-subtitled group.

\section{Movie 6: Man of Steel}

The task of this movie consisted of 12 items with the lowest possible score being 0 and the highest possible being 12. In this task, the mean score of the subtitled group is 10.95, while the non-subtitled group shows 10.05. It indicates that there is no significant difference between the mean score of the subtitled and non-subtitled groups. The highest scores for both groups also show 12. These calculations indicate that both the subtitled and non-subtitled groups have very good results.

The results of the data analysis of the six movie tasks indicate a positive effect for the subtitled and non-subtitled groups. Both groups significantly improved during 6 weeks. It was also revealed that the subtitled group demonstrated better results than the non-subtitled group. The subtitled group outperformed the non-subtitled group in 5 of the 6 movie tasks. In the last movie task, there was no significant difference between the subtitled and non-subtitled groups, but the results still showed that subtitled group performed better than non-subtitled group.

For the differences between the subtitled and non-subtitled groups, it indicates that the alternative hypothesis $\left(\mathrm{H}_{1}\right)$ was accepted and, of course, the null hypothesis $\left(\mathrm{H}_{0}\right)$ was rejected. It can be concluded that general (IELTS listening test) and immediate (Movie tasks) progress show different levels of 
SyamE Rahman, Subtitle Films and Learning Listening Comprehension $\mid 69$

improvement between the subtitled and non-subtitled groups in learning listening comprehension.

\section{DISCUSSION}

The researcher found two issues related to the possible effects of movie subtitling on listening comprehension. First, the immediate effect of both the subtitled and non-subtitled groups was taken into account. The result of the data analysis indicated a positive effect for both groups. It also revealed that the subtitled group performed better on the immediate comprehension than the non-subtitled group. Second, when it comes to the improvement of listening comprehension in general (the IELTS listening test), it was found that neither of the procedures (presenting the movie with or without subtitles) resulted in a better performance. Although, the data analysis of the IELTS listening test indicated that the non-subtitled group had a better mean score compared to the subtitled group, the improvement of the non-subtitled and subtitled groups both remained in the low to the mid-skill levels based on the IELTS marking criteria.

When it comes to the immediate effect of subtitling, the recent literature indicates a positive role in one way or the other. In line with Markham (1989), who studied the role of subtitles on comprehension enhancement, the present research produced similar results for the listening test. Moreover, in agreement with Guillory (1999) and Huang \&Eskey (1999-2000), the non-subtitled group came last when immediate comprehension was focused. All of the studies, which supported the use of subtitles, however, suffered from a major shortcoming. Those researchers neglected to test their subjects with a test, whichwas not subtitled, such as the IELTS listening test, which is used in the present study as a means to test the general listening improvement of the learners. This may explain the better performance of the non-subtitled group on the IELTS test, since they were used to receiving no support from subtitles during instruction using movies.

\section{CONCLUSION}

Presenting movies with and without subtitles in teaching listening comprehension was demonstrated to have a positive effect on the students' IELTS listening test achievement scores. The mean score of the nonsubtitled group (from 8.9 to 12.6 ) was substantially higher than the subtitled group (from 8.4 to 10.9). This test verified that the skill level of subtitled group stayed in same range of skill levels, while non-subtitled group increased from the limited to the modest skill level.

In terms of the difference in listening comprehension between subtitled and non-subtitled groups listening comprehension, movie task results showed 
70 | ELT Worldwide Vol. 1 No. 1

adifference between subtitled and non-subtitled group achievement. The subtitled group performed better the than the non-subtitled group.

It is suggested that a teacher or lecturer should present movies with or without subtitles to improve students' listening comprehension. In presenting movies to teach listening skills, it is suggested that it is better to use movies without subtitles rather than movies with subtitles in order to enhance the students' listening abilities.

\section{REFERENCES}

Barker, L.L. (1971). Listening behaviour.Englewood Cliffs, NJ:PrenticeHall.

Cayer, R. L., Green, J., \& Baker, E. E., Jr. (1971). Listening and speaking in the English classroom: A Collection of Readings. New York: Macmillan.

Coakley, C.\&Wolvin, A. (1997). Listening in the educational environment. In M. Purdy \& D. Borisoff (Eds.), Listening in Everyday Life: A Personal and Professional Approach (2nd ed.) (pp. 179-212). Lanham: University Press of America.

Curtain, H. A. \&Pesola, C. A. (1988). Language and children -- Making the match: Foreign language instruction in the elementary school. Reading: Addison-Wesley.

Dunkel, P. (1986). Developing listening fluency in L2: Theoretical principles and pedagogical considerations. The Modern Language Journal, 70, 99-106.

Dunkel, P. A. (1991). Listening in the native and second/foreign language: Toward an integration of research and practice. TESOL Quarterly, 25, 431-457.

Gay, L. (2006). Educational research: Competencies for analysis and applications.Pearson Education, Inc.

Guillory, H.G. (1999). The effect of keyword captions to authentic French video on learner comprehension.CALICO Journal, 15(1-3), 89-108.

Markham, P. (1989). The effects of captioned television video tapes on the listening comprehension of beginning, intermediate and advanced ESL students.Educational Technology, 29(10), 3-41.

Rankin, P.T. (1930). Listening ability: Its importance, measurement, and development. Chicago School Journal, 12, 177-9.

Taylor, S. (1964). Listening: What research says to the teacher. Washington, DC: National Education Association. 